\title{
Photovoltaic Performance of Perovskite Solar Cells with Different Grain Sizes.
}

\section{$\operatorname{AUTHOR}(S)$ :}

Kim, Hyung Do; Ohkita, Hideo; Benten, Hiroaki; Ito, Shinzaburo

\section{CITATION:}

Kim, Hyung Do ... [et al]. Photovoltaic Performance of Perovskite Solar Cells with Different Grain Sizes.. Advanced materials 2015, 28(5): $917-$ 922

\section{ISSUE DATE:}

2015-12-07

URL:

http://hdl.handle.net/2433/202519

\section{RIGHT:}

This is the peer reviewed version of the following article: [Kim, H. D., Ohkita, H., Benten, H. and Ito, S. (2015),

Photovoltaic Performance of Perovskite Solar Cells with Different Grain Sizes. Advanced Materials, Early View], which has been published in final form at http://dx.doi.org/10.1002/adma.201504144. This article may be used for noncommercial purposes in accordance with Wiley Terms and Conditions for Self-Archiving.; The full-text file will be made open to the public on 7 DEC 2016 in accordance with publisher's 'Terms and Conditions for Self-Archiving'.: This is not the published version. Please cite only the published version.; この論文は出版社版でありません。引用の際には出版社 版をご確認ご利用ください。 
DOI: 10.1002/adma.((please add manuscript number))

\title{
Photovoltaic Performance of Perovskite Solar Cells with Different Grain Sizes
}

\author{
By Hyung Do Kim, Hideo Ohkita, * Hiroaki Benten, and Shinzaburo Ito
}

H. D. Kim, Dr. H. Ohkita, Dr. H. Benten, Prof. S. Ito

Department of Polymer Chemistry, Graduate School of Engineering, Kyoto University, Katsura, Nishikyo, Kyoto 615-8510, Japan

E-mail: ohkita@photo.polym.kyoto-u.ac.jp

Dr. H. Ohkita

Japan Science and Technology Agency (JST), PRESTO, 4-1-8 Honcho, Kawaguchi, Saitama 332-0012, Japan.

Keywords: halide perovskites; grain sizes; open-circuit voltages; direct recombinations; trapassisted SRH recombinations

Perovskite solar cells based on organometal halides such as $\mathrm{CH}_{3} \mathrm{NH}_{3} \mathrm{PbI}_{3}\left(\mathrm{MAPbI}_{3}\right)$ and $\mathrm{CH}_{3} \mathrm{NH}_{3} \mathrm{PbI}_{3-x} \mathrm{Cl}_{x}\left(\mathrm{MAPbI}_{3-x} \mathrm{Cl}_{x}\right)$ have made rapid progress in the past several years. As a result, the power conversion efficiency (PCE) has been improved drastically from 3.8 to more than $20 \% .^{[1-6]}$ Recent studies have shown that such efficient device performance is due to excellent light-harvesting properties, ${ }^{[7]}$ long charge carrier diffusion lengths, ${ }^{[8,9]}$ high charge carrier mobility, ${ }^{[10,11]}$ ultrafast charge generation and slow charge carrier recombination, ${ }^{[10-12]}$ and small exciton binding energy. ${ }^{[13-17]}$ On the other hand, the photovoltaic performance is highly sensitive to fabrication conditions of perovskites, which have critical impact on the morphology of perovskite films. ${ }^{[18-23]}$ Consequently, perovskite solar cells typically exhibit wide variations in the device efficiency even though they are fabricated by the same fabrication methods. This is probably because the crystalline growth of perovskite materials cannot be well controlled for efficient photovoltaic performance. As such, much effort has been devoted to obtaining uniform and dense perovskite layers with high reproducibility.

Very recently, several groups have reported solution-processed fabrication methods based on solvent engineering for obtaining uniform and dense perovskite layers with high reproducibility. Seok and co-workers reported that uniform and dense perovskite layers can be 


\section{Submitted to \\ ADVANCED}

obtained by spin-coating from a mixture solution of $\gamma$-butyrolactone and $N, N$ dimethylformamide (DMF), followed by toluene dripping during the spin-coating. ${ }^{[18]}$ Independently, Cheng and co-workers reported that flat and uniform perovskite thin films can be obtained by a fast deposition-crystallization (FDC) method involving spin-coating from a DMF solution followed by chlorobenzene dripping during the spin-coating to induce crystallization. ${ }^{[23]}$ Subsequently, Huang and co-workers reported that solvent annealing effectively increases the crystallinity and grain size of $\mathrm{CH}_{3} \mathrm{NH}_{3} \mathrm{PbI}_{3}\left(\mathrm{MAPbI}_{3}\right)$ films. ${ }^{[24]}$ The average grain size can be increased up to $1 \mu \mathrm{m}$ by this method. All these fabrication methods based on solvent engineering give flat, uniform, and dense perovskite films with high reproducibility. As a result, PCE has been improved to around $15 \%$.

Herein we have prepared uniform and dense $\mathrm{MAPbI}_{3}$ perovskite layers with different grain sizes by the FDC procedure ${ }^{[23]}$ and fabricated simple planar heterojunction solar cells without mesoporous scaffolds to avoid mixture of different sized grains formed in mesoporous and capping layers. By analyzing the intensity-dependent open-circuit voltage ( $\left.V_{\mathrm{OC}}\right)$ on the basis of the Shockley-Read-Hall (SRH) model, we have shown that trap density increases with decreasing grain size, resulting in decreasing $V_{\mathrm{OC}}$. These findings indicate that there is still room for improvement in $V_{\mathrm{OC}}$ in working devices. We further discuss the potential for enhancement in photovoltaic performance. 


\section{Submitted to

As shown in Figure 1, MAPbI 3 perovskite films fabricated by the FDC procedure are dense and pin-hole free with relatively uniform grain sizes over the entire substrate. This is in sharp contrast with $\mathrm{MAPbI}_{3}$ perovskite films with a poor coverage deposited by the conventional one-step spin-coating method as reported previously ${ }^{[2,22,23,25]}$ (see Figure S1 in the Supporting Information). As shown in Figure 2a, the grain size of the perovskite films fabricated by the FDC procedure increases with increasing concentration of the stock solution used to prepare the perovskite layer. These grain sizes obtained are consistent with those observed in scanning electron microscopy (SEM) images (see the Supporting Information).
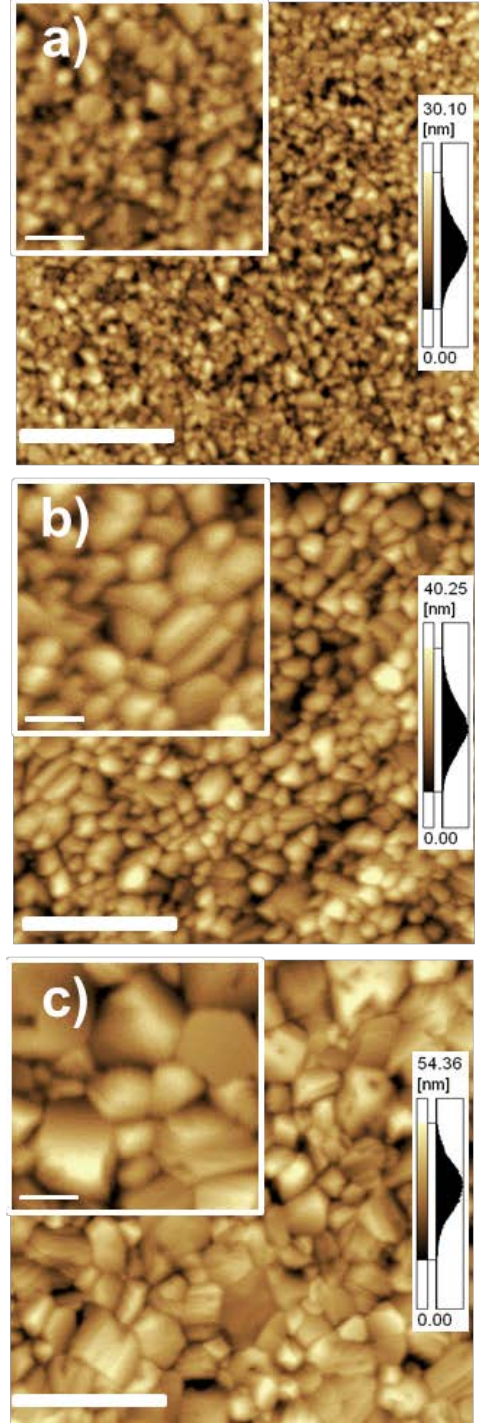

Figure 1. AFM height images $(3 \mu \mathrm{m} \times 3 \mu \mathrm{m})$ of $\mathrm{MAPbI}_{3}$ perovskite films prepared from a) $25 \mathrm{wt} \%$ stock solution, b) $45 \mathrm{wt} \%$ stock solution, and c) $55 \mathrm{wt} \%$ stock solution. The scale bars correspond to $1 \mu \mathrm{m}$ in length. The inset in each figure is an enlarged image of the same film and the scale bars correspond to $250 \mathrm{~nm}$ in length. 
Submitted to

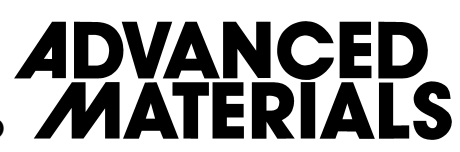

The grain size of $\mathrm{MAPbI}_{3}$ showed a wider distribution with increasing concentration of stock solution. These trends are in good agreement with the previous report. ${ }^{[23]}$ The average grain size of $\mathrm{MAPbI}_{3}$ is estimated to be $\approx 100 \mathrm{~nm}$ for $25 \mathrm{wt} \%$ stock solution, $\approx 300 \mathrm{~nm}$ for $45 \mathrm{wt} \%$ stock solution, and $\approx 500 \mathrm{~nm}$ for $55 \mathrm{wt} \%$ stock solution. Interestingly, as shown in Figure $2 \mathrm{~b}$, the thickness of the perovskite layer $L$ is the same as the grain size. This finding indicates that the perovskite layer consists of monograins in the direction normal to the substarte, which is consistent with the cross-sectional SEM images (see the Supporting Information).

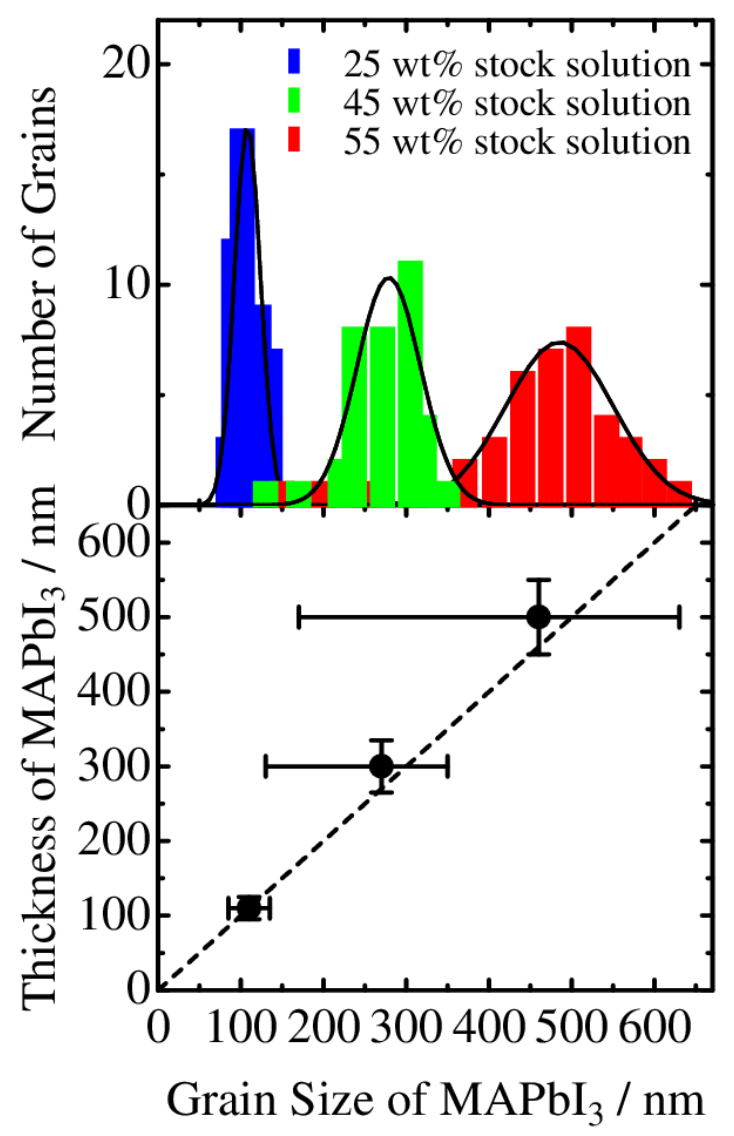

Figure 2. a) Histogram for $\mathrm{MAPbI}_{3}$ perovskite films with different grain sizes. The solid lines show a Gaussian fitting curve. b) Thickness of $\mathrm{MAPbI}_{3}$ perovskite films plotted against the grain size of $\mathrm{MAPbI}_{3}$ perovskite film. The closed circles and error bars in $x$-axis and in $y$-axis represent the average and the standard deviation of eight different points in $\mathrm{MAPbI}_{3}$ perovskite films, respectively. The broken line represents a linear function. 
Submitted to

To examine how grain size affects the photovoltaic properties of halide perovskite solar cells, we fabricated $\mathrm{MAPbI}_{3}$ solar cells with different grain sizes by the FDC method. The device structure is based on a planar heterojunction in which the perovskite layer is sandwiched with an electron-transporting layer of dense $\mathrm{TiO}_{2}$ and a hole-transporting layer of $2,2^{\prime}, 7,7^{\prime}$ tetrakis(N,N-di-p-methoxyphenylamine)-9,9-spirobifluorene (spiro-OMeTAD). $\quad$ Figure 3 shows the $J-V$ characteristics of $\mathrm{MAPbI}_{3}$ solar cells with different gran sizes. Note that the $J_{-}$ $V$ characteristics in Figure 3 were measured from 1.2 to $-0.10 \mathrm{~V}$ (reverse scan) with a delay time of $1 \mathrm{~s}$. All the photovoltaic parameters were improved with increasing grain size as shown in Figure S4 (Supporting Information). As a result, the best PCE of 19.4\% was obtained for $\mathrm{MAPbI}_{3}$ perovskite solar cells with the largest grain size of $\approx 500 \mathrm{~nm}$ : a short-circuit current density $\left(J_{\mathrm{SC}}\right)$ of $23.91 \mathrm{~mA} \mathrm{~cm}^{-2}$, an open-circuit voltage $\left(V_{\mathrm{OC}}\right)$ of $1.08 \mathrm{~V}$, and a fill factor $(\mathrm{FF})$ of 0.750 . Note that $J-V$ characteristics in the steady state, histograms of the device parameters, and long-term stability are summarized in the Supporting Information. The large $J_{\mathrm{SC}}$ is in good agreement with the photocurrent $\left(23.50 \mathrm{~mA} \mathrm{~cm}{ }^{-2}\right)$ calculated from the external quantum efficiency (EQE) spectrum as described below. As shown in Figure S8 (Supporting Information), $J-V$ hysteresis were observed for the forward and reverse measurements, which

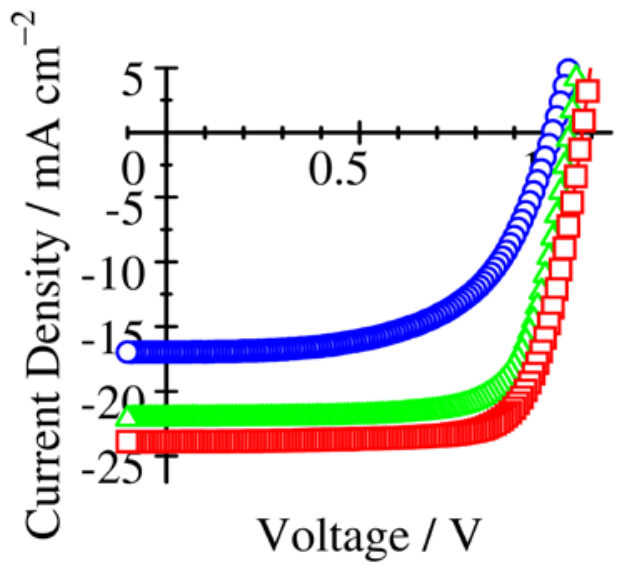

Figure 3. $J-V$ characteristics of $\mathrm{MAPbI}_{3}$ perovskite solar cells with different grain sizes measured from 1.2 to $-0.10 \mathrm{~V}$ (reverse scan) with a delay time of $1 \mathrm{~s}: \approx 100 \mathrm{~nm}$ (blue open circles), $\approx 300 \mathrm{~nm}$ (green open triangles), and $\approx 500 \mathrm{~nm}$ (red open squares). All the devices were measured in a nitrogen atmosphere with a metal mask to give an active area of $0.09 \mathrm{~cm}^{2}$. 


\section{Submitted to \\ ADANACED
MAATRRALIS}

a)

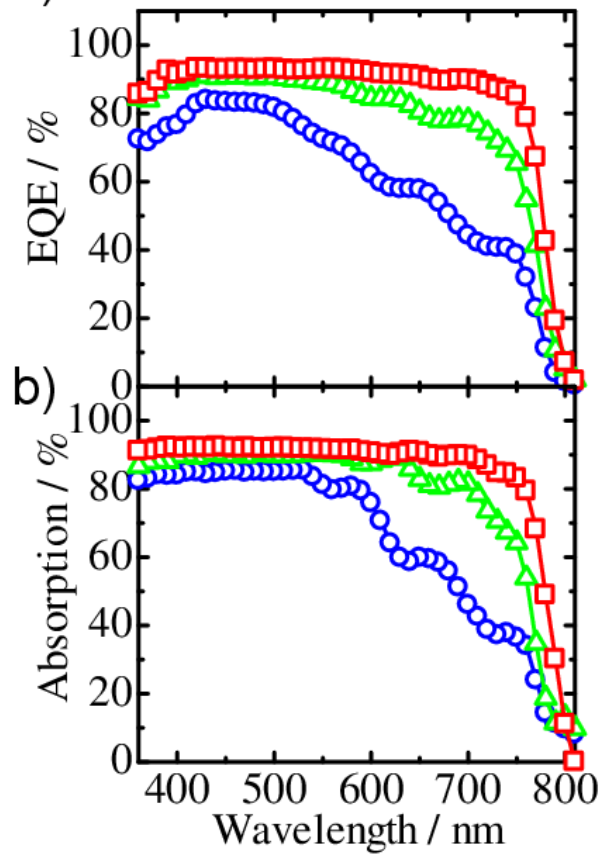

Figure 4. a) EQE spectra and b) Reflection absorption spectra of $\mathrm{MAPbI}_{3}$ perovskite solar cells (FTO/dense- $\mathrm{TiO}_{2} /$ perovskites/HTM/Au): $\mathrm{MAPbI}_{3}$ films with a grain size of $\approx 100 \mathrm{~nm}$ (blue open circles), $\approx 300 \mathrm{~nm}$ (green open triangles), and $\approx 500 \mathrm{~nm}$ (red open squares).

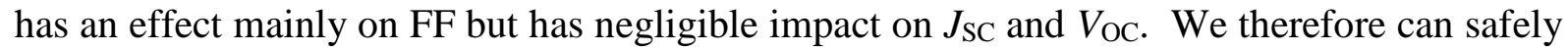
discuss the origin of the improvement in $J_{\mathrm{SC}}$ and $V_{\mathrm{OC}}$ regardless of the hysteresis.

In order to discuss the photocurrent improvement, we measured the EQE spectra of the three devices. As shown in Figure 4a, the EQE signals decreased at longer wavelengths for the devices with smaller grain sizes but were almost saturated at more than $80 \%$ over the wide wavelength range from 350 to $750 \mathrm{~nm}$ for the device with the largest grain. The same trend was found in the absorption spectra measured in the reflectance mode as shown in Figure 4b. This good agreement indicates that the photocurrent improvement is primarily attributed to the enhanced absorption due to the thicker active layer with larger grains. From the EQE and absorption spectra, the internal quantum efficiency was estimated to be almost $100 \%$ for $\mathrm{MAPbI}_{3}$ perovskite solar cells with the largest grain size. Such a low reflection loss is in good 
Submitted to

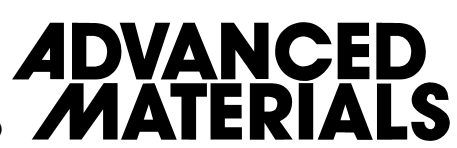

agreement with a recent study on the optical properties of planar heterojunction $\mathrm{MAPbI}_{3}$ solar cells. ${ }^{[26]}$ Our finding also suggests that these are negligible losses in the charge generation and collection even in thicker perovskite devices.

We next focus on the improvement in $V_{\mathrm{OC}}$ for $\mathrm{MAPbI}_{3}$ perovskite solar cells with the larger grain size. In order to address the origin of the improved $V_{\mathrm{OC}}$, we measured the intensity dependence of $V_{\mathrm{OC}}$ for the three devices as discussed in previous studies. ${ }^{[27-29]}$ Under typical conditions, $V_{\mathrm{OC}}$ is given by:

$$
V_{\mathrm{OC}}=\frac{n_{\mathrm{id}} k_{\mathrm{B}} T}{q} \ln \left(\frac{J_{\mathrm{SC}}}{J_{0}}\right)
$$

where $n_{\text {id }}$ is the ideality factor, $k_{\mathrm{B}}$ is the Boltzmann constant, $T$ is temperature, $q$ is the elementary charge, and $J_{0}$ is the saturation current density at reverse bias. Thus, the ideality factor is estimated from a slope in plots of $V_{\mathrm{OC}}$ against the logarithm of $J_{\mathrm{SC}}$. As shown in Figure $5, n_{\text {id }}$ decreased from 2.7 to 1.5 with increasing grain size from $\approx 100$ to $\approx 500 \mathrm{~nm}$. In general, the direct recombination gives an ideality factor of unity and the Shockley-Read-Hall (SRH) recombination gives an ideality factor of 2 under a typical condition. ${ }^{[30,31]}$ Here, we will analyze the intensity-dependent $V_{\mathrm{OC}}$ by considering both direct and SRH recombinations.

Under the open-circuit condition, $V_{\mathrm{OC}}$ is equal to the difference between the quasi-Fermi levels $\left(E_{\mathrm{f}}^{\mathrm{h}}-E_{\mathrm{f}}^{\mathrm{e}}\right)$ and hence is generally given by:

$$
q V_{\mathrm{OC}}=E_{\mathrm{g}}-k_{\mathrm{B}} T \ln \left(\frac{N_{\mathrm{C}} N_{\mathrm{V}}}{n p}\right)
$$

where $E_{\mathrm{g}}$ is the bandgap nergy, $N_{\mathrm{C}}$ and $N_{\mathrm{V}}$ are the effective density of states in conduction and valence bands, respectively, and $n$ and $p$ are the density of electrons and that of holes, respectively. ${ }^{[27,28,32]}$ The bimolecular radiative recombination rate $\left(R_{\mathrm{rad}}\right)$ is given by:

$$
R_{\mathrm{rad}}=B_{\mathrm{rad}}\left(n p-n_{\mathrm{i}} p_{\mathrm{i}}\right)
$$

where $n_{\mathrm{i}}$ and $p_{\mathrm{i}}$ are the intrinsic density of electrons and that of holes, respectively, and $B_{\text {rad }}$ is the radiative recombination coefficient. Here, $n$ and $p$ are given by $n=\Delta n+n_{0}$ and $p=\Delta p+p_{0}$ 


\section{Submitted to

where $\Delta n$ and $\Delta p$ are the density of electrons and that of holes photogenerated under the

illumination, respectively, and $n_{0}$ and $p_{0}$ are the density of electrons and that of holes generated

by unintentional doping given by Equation (4) and (5), respectively:

$$
\begin{aligned}
& n_{0}=N_{\mathrm{C}} \exp \left(\frac{E_{\mathrm{f}}-E_{\mathrm{C}}}{k_{\mathrm{B}} T}\right) \\
& p_{0}=N_{\mathrm{V}} \exp \left(\frac{E_{\mathrm{V}}-E_{\mathrm{f}}}{k_{\mathrm{B}} T}\right)
\end{aligned}
$$

On the other hand, the trap-assisted SRH recombination rate is given by:

$$
R_{\mathrm{SRH}}=B_{\mathrm{SRH}}\left(n p-n_{\mathrm{i}} p_{\mathrm{i}}\right)
$$

Here, $B_{\mathrm{SRH}}$ is given by:

$$
B_{\mathrm{SRH}}=\frac{C_{\mathrm{n}} C_{\mathrm{p}} N_{\mathrm{t}}}{C_{\mathrm{n}}\left(n+n_{1}\right)+C_{\mathrm{p}}\left(p+p_{1}\right)}
$$

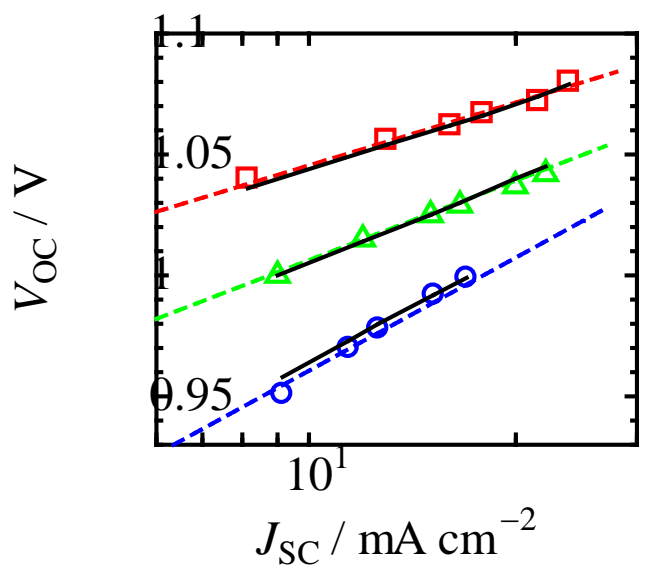

Figure 5. $V_{\mathrm{OC}}$ plotted against logarithm of $J_{\mathrm{SC}}: \mathrm{MAPbI}_{3}$ films with a grain size of $\approx 100 \mathrm{~nm}$ (blue open circles), $\approx 300 \mathrm{~nm}$ (green open triangles), and $\approx 500 \mathrm{~nm}$ (red open squares). The broken lines represent the slope of 2.7, 1.9, and 1.5 for $\mathrm{MAPb}_{3}$ films with a grain size of $\approx 100 \mathrm{~nm}, \approx 300 \mathrm{~nm}$, and $\approx 500 \mathrm{~nm}$, respectively. The black solid lines are the calculated values on the basis of Equation (2) with different trap densities: $N_{\mathrm{t}}=5.30 \times 10^{16} \mathrm{~cm}^{-3}, 1.05 \times 10^{16} \mathrm{~cm}^{-3}, 2.84 \times 10^{15} \mathrm{~cm}^{-3}$ for $\mathrm{MAPbI}_{3}$ films with a grain size of $\approx 100 \mathrm{~nm}, \approx 300 \mathrm{~nm}$, and $\approx 500 \mathrm{~nm}$, respectively. In the calculation, $B_{\text {rad }}$ is fixed to $3.0 \times 10^{-9} \mathrm{~cm}^{3} \mathrm{~s}^{-1}$ for all the samples, ${ }^{[33]}$ which has little or no impact on the resultant fitting from $\approx 10^{-8}$ to $\approx 10^{-10} \mathrm{~cm}^{3} \mathrm{~s}^{-1}$. The other parameters are taken from the literatures: $N_{\mathrm{C}} N_{\mathrm{V}}=1.09 \times 10^{37} \mathrm{~cm}^{-3},{ }^{[34]} E_{\mathrm{C}}-E_{\mathrm{f}}=0.34 \mathrm{eV}, E_{\mathrm{C}}-E_{\mathrm{t}}=0.38 \mathrm{eV},{ }^{[35]}$ and $C_{\mathrm{n}}$ and $C_{\mathrm{p}}$ are set to be $1.0 \times 10^{-8}$ and $1.0 \times 10^{-5} \mathrm{~cm}^{3} \mathrm{~s}^{-1}$, respectively. ${ }^{[35]}$ 
Submitted to

\section{ADVANCED MATERIALS}

where $C_{\mathrm{n}}$ and $C_{\mathrm{p}}$ are the capture coefficients for electrons and holes at trapped sites, respectively, $N_{\mathrm{t}}$ is the density of trap states with an energy $E_{\mathrm{t}}$ in the bandgap, and $n_{1}$ and $p_{1}$ are given by:

$$
\begin{aligned}
& n_{1}=N_{\mathrm{C}} \exp \left(\frac{E_{\mathrm{t}}-E_{\mathrm{C}}}{k_{\mathrm{B}} T}\right) \\
& p_{1}=N_{\mathrm{V}} \exp \left(\frac{E_{\mathrm{V}}-E_{\mathrm{t}}}{k_{\mathrm{B}} T}\right)
\end{aligned}
$$

where $n_{1}$ and $p_{1}$ are the density of electrons and that of holes, respectively, when the Fermi levels of electron and hole are equal to the trap level. ${ }^{[36-38]}$ In Figure 6, the energy diagram of the SRH recombination is summarized. Under the open circuit condition, the charge generation rate $G=J_{\mathrm{SC}} / q L$ is equal to the total recombination rate $R=R_{\mathrm{rad}}+R_{\mathrm{SRH}}$. In other words, we obtain the relationship between $J_{\mathrm{SC}}$ and the carrier density $n$ and $p$. By substituting this relationship into Equation (2), we can simulate the dependence of $V_{\mathrm{OC}}$ on $J_{\mathrm{SC}}$. As shown in Figure 5, the intensity dependence of $V_{\mathrm{OC}}$ was well fitted with $E_{\mathrm{C}}-E_{\mathrm{t}}=0.38 \mathrm{eV}, E_{\mathrm{C}}-E_{\mathrm{f}}=0.34$ $\mathrm{eV}, N_{\mathrm{t}}=5.30 \times 10^{16} \mathrm{~cm}^{-3}$ for $\approx 100 \mathrm{~nm}, 1.05 \times 10^{16} \mathrm{~cm}^{-3}$ for $\approx 300 \mathrm{~nm}$, and $2.84 \times 10^{15} \mathrm{~cm}^{-3}$ for $\approx 500 \mathrm{~nm}$ grain sizes of $\mathrm{MAPbI}_{3}$. The other parameters employed are taken from the literatures: $N_{\mathrm{C}} N_{\mathrm{V}}=1.09 \times 10^{37} \mathrm{~cm}^{-3},{ }^{[34]} B_{\mathrm{rad}}=3.0 \times 10^{-9} \mathrm{~cm}^{3} \mathrm{~s}^{-1},{ }^{[33]} C_{\mathrm{n}}=1.0 \times 10^{-8} \mathrm{~cm}^{3} \mathrm{~s}^{-1}$, and $C_{\mathrm{p}}=1.0$ $\times 10^{-5} \mathrm{~cm}^{3} \mathrm{~s}^{-1}$. ${ }^{[35]}$ The values of $N_{\mathrm{t}}$ calculated on the basis of Equation (2) are in good agreement with the recent reports, ${ }^{[39,40]}$ suggesting that these parameters assumed here are consistent estimates. The values of $N_{\mathrm{t}}$ estimated from our samples are comparable to defect densities in

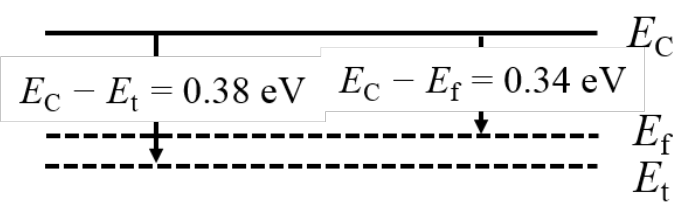

$$
E_{\mathrm{V}}
$$

Figure 6. Energy diagram of $\mathrm{MAPb}_{3}$ perovskites with an unintentional doping level $\left(E_{\mathrm{f}}\right)$ and a single trap level $\left(E_{\mathrm{t}}\right)$. 
Submitted to

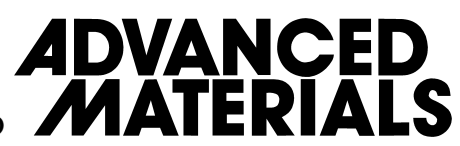

the highly ordered organic materials with single crystals, inclusive of rubrene and pentacene $\left(10^{15}-10^{18} \mathrm{~cm}^{-3}\right),{ }^{[41]}$ while they are higher than the values of $N_{\mathrm{t}}$ reported for a wide range of inorganic semiconductors, such as polycrystalline $\mathrm{Si}\left(10^{13}-10^{14} \mathrm{~cm}^{-3}\right),{ }^{[42]} \mathrm{CdTe} / \mathrm{CdS}\left(10^{11}-10^{13}\right.$ $\left.\mathrm{cm}^{-3}\right),{ }^{[43]}$ CIGS $\left(10^{13} \mathrm{~cm}^{-3}\right),{ }^{[44]}$ and GaAs $\left(10^{13}-10^{15} \mathrm{~cm}^{-3}\right) \cdot{ }^{[38]}$ In our analysis, the trap depth energy $E_{\mathrm{C}}-E_{\mathrm{t}}$ is evaluated to be $0.38 \mathrm{eV}$ for all the grain sizes, which is in good agreement with the trap depth calculated for the vacancy of I. ${ }^{[35]}$ The unintentional doping level $E_{\mathrm{C}}-E_{\mathrm{f}}$ is evaluated to be as shallow as $0.34 \mathrm{eV}$ independently of the grain sizes. Such a shallow doping level causes imbalance carrier density of electron and hole because of unintentional doping, resulting in the ideality factor of less than 2 or more than 2. Interestingly, the unintentional doping level $E_{\mathrm{C}}-E_{\mathrm{f}}$ is close to the $E_{\mathrm{C}}-E_{\mathrm{t}}=0.38 \mathrm{eV}$, suggesting that the vacancy of $\mathrm{I}$ is the origin of unintentional doping and serves as a trap site. We note that the intensity-dependent $V_{\text {OC }}$ can be explained by the SRH recombination alone with the same parameters mentioned above, which are consistent with literature values evaluated by different methods. In other words, the trap-assisted SRH recombination is the primary loss mechanism in $\mathrm{MAPbI}_{3}$ halide perovskite solar cells. This is probably because our perovskite solar cells are highly efficient and hence have less recombination loss mechanisms.

We further discuss the potential for improvement in $V_{\mathrm{OC}}$ in $\mathrm{MAPbI}_{3}$ perovskite solar cells. As mentioned above, $N_{\mathrm{t}}$ in our $\mathrm{MAPbI}_{3}$ perovskite films is comparable to that in organic semiconductor crystals but still higher than that in inorganic semiconductors. In other words, there is still room for improvement in $N_{\mathrm{t}}$ and hence $V_{\mathrm{OC}}$. Indeed, Shi et al. reported recently that the single perovskite grain with millimeter scale exhibits extremely low trap state densities on the order of $10^{9}-10^{10} \mathrm{~cm}^{-3} \cdot{ }^{[45]}$ Assuming such low $N_{\mathrm{t}}$ in our analysis, $V_{\mathrm{OC}}$ would be improved up to $\approx 1.27 \mathrm{~V}$ as shown in Figure 7, which is comparable to Shockley-Queisser theoretical limit value of $\approx 1.30 \mathrm{~V} .^{[46]}$ This is also consistent with a numerical simulation in planar perovskite solar cells. ${ }^{[39]}$ On the other hand, a recent study has shown that perovskite solar cells with millimeter-scale grains exhibit a high PCE of $18 \%$ with an ideality factor of almost unity. ${ }^{[47]}$ 


\section{Submitted to

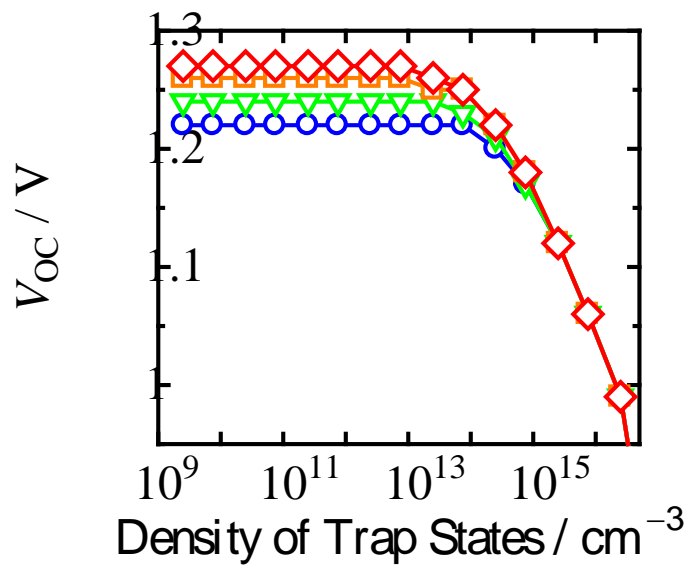

Figure 7. $V_{\mathrm{OC}}$ plotted against logarithm of $N_{\mathrm{t}}$ for the $\mathrm{MAPbI}_{3}$ perovskite film with a grain size of $\approx 500 \mathrm{~nm}$. The radiative recombination coefficient $\left(B_{\mathrm{rad}}\right)$ employed is taken from the literatures: ${ }^{[33,48]} B_{\mathrm{rad}}=3.0 \times 10^{-9} \mathrm{~cm}^{3} \mathrm{~s}^{-1}$ (blue open circles), $B_{\mathrm{rad}}=1.5 \times 10^{-9} \mathrm{~cm}^{3} \mathrm{~s}^{-1}$ (green open triangles), $B_{\text {rad }}=8.0 \times 10^{-10} \mathrm{~cm}^{3} \mathrm{~s}^{-1}$ (orange open squares), and $B_{\text {rad }}=5.0 \times 10^{-10} \mathrm{~cm}^{3} \mathrm{~s}^{-1}$ (red open diamonds). Here, $J_{\mathrm{SC}}$ is fixed to $24 \mathrm{~mA} \mathrm{~cm}^{-2}$.

However, the $V_{\text {OC }}$ reported is not as high as predicted above but rather smaller than that of our device with a much smaller grain size of $\approx 500 \mathrm{~nm}$. The smaller $V_{\text {OC }}$ with an ideality factor of almost unity cannot be explained by direct and SRH recombination alone, suggesting that other loss mechanisms are involved in the perovskite solar cell with millimeter-scale grains. For instance, such a small $V_{\text {oc }}$ may be due to the difference in the energy level alignment or surface recombination at the interface as reported previously. ${ }^{[49-51]}$ We therefore should consider not only trap density but also other recombination mechanisms such as surface recombination in order to improve $V_{\mathrm{OC}}$ furthermore.

In conclusion, we have demonstrated planar heterojunction perovskite solar cells with a layer structure of $\mathrm{FTO} /$ dense- $\mathrm{TiO}_{2} / \mathrm{MAPbI}_{3} /$ spiro-OMeTAD/Au. The $\mathrm{MAPb}_{3}$ perovskite layer was fabricated by the FDC procedure. By controlling the stock solution concentration, we obtained dense $\mathrm{MAPbI}_{3}$ layers with different grain sizes ranging from $\approx 100$ to $\approx 500 \mathrm{~nm}$. With increasing grain size of perovskites, all the photovoltaic parameters were improved. As a result, the best performance was observed in the reverse scan for the largest grain size ( $\approx 500 \mathrm{~nm})$ of 
Submitted to

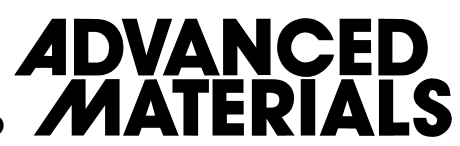

MAPbI $_{3}$ perovskite: a PCE of $19.4 \%$, a $J_{\mathrm{SC}}$ of $23.91 \mathrm{~mA} \mathrm{~cm}^{-2}$, a $V_{\text {OC }}$ of $1.08 \mathrm{~V}$, and an FF of

0.750. The improved $J_{\mathrm{SC}}$ is ascribed mainly to the thicker active layer, which results in improved light-harvesting properties. On the other hand, the improved $V_{\mathrm{OC}}$ is analyzed by a combination model of the radiative recombination and the trap-assisted SRH recombination. The enhancement in $V_{\text {OC }}$ from 1.00 to $1.08 \mathrm{~V}$ is due to the decrease in trap density $N_{\mathrm{t}}$ from 5.30 $\times 10^{16}$ to $2.84 \times 10^{15} \mathrm{~cm}^{-3}$. This trap density is comparable to that reported for organic semiconductor crystals but higher than that for inorganic semiconductors. In other words, $V_{\mathrm{OC}}$ would be further improved by using purer perovskite grains with lower trap density. If $N_{\mathrm{t}}$ of perovskite films was suppressed to the order of $<10^{13} \mathrm{~cm}^{-3}$ as reported for mm-scale perovskite crystals, $V_{\text {OC }}$ could be improved up to $\approx 1.27 \mathrm{~V}$, which is comparable to the Shockley-Queisser theoretical limit. We also note that the $V_{\text {OC }}$ may be limited below the theoretical limitation if other recombination mechanisms such as surface recombination are involved. Nonetheless, our findings provide deep insight into the relationship between the photovoltaic performance and the grain size of perovskites. We thus emphasize that $\mathrm{MAPbI}_{3}$ perovskite solar cells have potential to exhibit the theoretical limit voltage.

\section{Supporting Information}

Supporting Information is available.

\section{Acknowledgments}

This work was partly supported by the JST PRESTO program (Photoenergy conversion systems and materials for the next generation solar cells).

Received: ((will be filled in by the editorial staff))

Revised: ((will be filled in by the editorial staff)) Published online: ((will be filled in by the editorial staff))

[1] M. A. Green, A. Ho-Baillie, H. J. Snaith, Nat. Photonics 2014, 8, 506.

[2] P. Gao, M. Grätzel, M. K. Nazeeruddin, Energy Environ. Sci. 2014, 7, 2448.

[3] T. C. Sum, N. Mathews, Energy Environ. Sci. 2014, 7, 2518. 
Submitted to UALERALS

\section{ADVANCED}

[4] M. A. Green, K. Emery, Y. Hishikawa, W. Warta, E. D. Dunlop, Prog. Photovoltaics: Res. Appl. 2015, 23, 805.

[5] W. S. Yang, J. H. Noh, N. J. Jeon, Y. C. Kim, S. Ryu, J. Seo, S. I. Seok, Science 2015, 348,1234

[6] A. Kojima, K. Teshima, Y. Shirai, T. Miyasaka, J. Am. Chem. Soc. 2009, 131, 6050.

[7] M. M. Lee, J. Teuscher, T. Miyasaka, T. N. Murakami, H. J. Snaith, Science 2012, 338, 643.

[8] S. D. Stranks, G. E. Eperson, G. Grancini, C. Menelaou, M. J. P. Alcocer, T. Leijtens, L. M. Herz, A. Petrozza, H. J. Snaith, Science 2013, 342, 341.

[9] G. Xing, N. Mathews, S. Sun, S. S. Lim, Y. M. Lam, M. Grätzel, S. Mhaisalkar, T. C. Sum, Science 2013, 342, 344.

[10] C. Wehrenfennig, G. E. Eperon, M. B. Johnston, H. J. Snaith, L. M. Herz, Adv. Mater. 2014, 26, 1584.

[11] C. S. Ponseca. Jr, T. J. Savenije, M. Abdellah, K. Zheng, A. Yartsev, T. Pascher, T. Harlang, P. Chabera, T. Pullerits, A. Stepanov, J. P. Wolf, V. Sundström, J. Am. Chem. Soc. 2014, 136, 5189.

[12] F. Deschler, M. Price, S. Pathak, L. E. Klintberg, D. D. Jarausch, R. Higler, S. Hüttner, T. Leijtens, S. D. Stranks, H. J. Snaith, M. Atatüre, R. T. Phillips, R. H. Friend, J. Phys. Chem. Lett. 2014, 5, 1421.

[13] V. DInnocenzo, G. Grancini, M. J. P. Alcocer, A. R. S. Kandada, S. D. Stranks, M. M. Lee, G. Lanzani, H. J. Snaith, A. Petrozza, Nat. Commun. 2014, 5, 3586.

[14] M. Saba, M. Cadelano, D. Marongiu, F. Chen, V. Sarritzu, N. Sestu, C. Figus, M. Aresti, R. Piras, A. G. Lehmann, C. Cannas, A. Musinu, F. Quochi, A. Mura, G. Bongiovanni, Nat. Commun. 2014, 5, 5049

[15] K. Tanaka, T. Takahashi, T. Ban, T. Kondo, K. Uchida, N. Miura, Solid State Commun. 2003, 127, 619. 
Submitted to

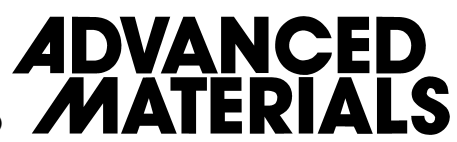

[16] K. Wu, A. Bera, C. Ma, Y. Du, Y. Yang, L. Li, T. Wu, Phys. Chem. Chem. Phys. 2014, 16, 22476.

[17] Y. Yamada, T. Nakamura, M. Endo, A. Wakamiya, Y. Kanemitsu, IEEE. J. Photovoltaics 2015, 5, 401.

[18] N. J. Jeon, J. H. Noh, Y. C. Kim, W. S. Yang, S. Ryu, S. I. Seok, Nat. Mater. 2014, 13, 897.

[19] D. Liu, T. L. Kelly, Nat. Photonics 2014, 8, 133.

[20] J. H. Im, I. H. Jang, N. Pellet, M. Grätzel, N. G. Park, Nat. Nanotechnol. 2014, 9, 927.

[21] H. Zhou, Q. Chen, G. Li, S. Luo, T. Song, H. S. Duan, Z. Hong, J. You, Y. Liu, Y. Yang, Science 2014, 345, 542.

[22] G. E. Eperon, V. M. Burlakov, P. Docampo, A. Goriely, H. J. Snaith, Adv. Funct. Mater. 2014, 24, 151.

[23] M. Xiao, F. Huang, W. Huang, Y. Dkhissi, Y. Zhu, J. Etheridge, A. Gray-Weale, U. Bach, Y. B. Cheng, L. Spiccia, Angew. Chem. 2014, 126, 10056.

[24] Z. Xiao, Q. Dong, C. Bi, Y. Shao, Y. Yuan, J. Huang, Adv. Mater. 2014, 26, 6503.

[25] H. L. Hsu, C. P. Chen, J. Y. Chang, Y. Y. Yu, Y. K. Shen, Nanoscale 2014, 6, 10281.

[26] J. M. Ball, S. D. Stranks, M. T. Hörantner, S. Hüttner, W. Zhang, E. J. W. Crossland, I. Ramirez, M. Riede, M. B. Johnston, R. H. Friend, H. J. Snaith, Energy. Environ. Sci. 2015, 8, 602

[27] L. J. A. Koster, V. D. Mihailetchi, R. Ramaker, P. W. M. Blom, Appl. Phys. Lett. 2005, $86,123509$.

[28] M. M. Mandoc, F. B. Kooistra, J. C. Hummelen, B. de Boer, P. W. M. Blom, Appl. Phys. Lett. 2007, 91, 263505.

[29] S. R. Cowan, W. L. Leong, N. Banerji, G. Dennler, A. J. Heeger, Adv. Funct. Mater. 2011, 21, 3083.

[30] C. T. Sah, R. N. Noyce, W. Shockley, Proc. IRE. 1957, 45, 1228. 
Submitted to

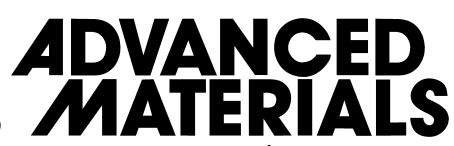

[31] G. J. A. H. Wetzelaer, M. Scheepers, A. M. Sempere, C. Momblona, J. Ávila, H. J. Bolink, Adv. Mater. 2015, 27, 1837.

[32] M. Kuik, L. J. A. Koster, G. A. H. Wetzelaer, P. W. M. Blom, Phys. Rev. Lett. 2011, 107, 256805.

[33] V. DInnocenzo, A. R. S. Kandada, M. D. Bastiani, M. Gandini, A. Petrozza, J. Am. Chem. Soc. 2014, 136, 17730.

[34] W. J. Yin, J. H. Yang, J. Kang, Y. Yan, S. H. Wei, J. Mater. Chem. A. 2015, 3, 8926.

[35] M. L. Agiorgousis, Y. Y. Sun, H. Zeng, S. Zhang, J. Am. Chem. Soc. 2014, 136, 14570.

[36] D. Macdonald, A. Cuevas, Phys. Rev. B 2003, 67, 075203.

[37] M. Maiberg, R. Scheer, J. Appl. Phys. 2014, 116, 123710.

[38] C. R. Haughn, K. J. Schmieder, J. M. O. Zide, A. Barnett, C. Ebert, R. Opila, M. F. Doty, Appl. Phys. Lett. 2013, 102, 182108.

[39] F. Liu, J. Zhu, J. Wei, Y. Li, M. Lv, S. Yang, B. Zhang, J. Yao, S. Dai, Appl. Phys. Lett. 2014, 104, 253508.

[40] G. Xing, N. Mathews, S. S. Lim, N. Yantara, X. Liu, D. Sabba, M. Grätzel, S. Mhaisalkar, T. C. Sum, Nat. Mater. 2014, 13, 476.

[41] S. Mehraeen, V. Coropceanu, J. L. Brédas, Phys. Rev. B 2013, 87, 195209.

[42] I. Capan, V. Borjanović, B. Pivac, Sol. Energy Mater. Sol. Cells. 2007, 91, 931.

[43] A. Balcioglu, R. K. Ahrenkiel, F. Hasoon, J. Appl. Phys. 2000, 88, 7175.

[44] L. L. Kerr, S. S. Li, S. W. Johnston, T. J. Anderson, O. D. Crisalle, W. K. Kim, J. Abushama, R. N. Noufi, Solid-State Electron. 2004, 48, 1579.

[45] D. Shi, V. Adinolfi, R. Comin, M. Yuan, E. Alarousu, A. Buin, Y. Chen, S. Hoogland, A. Rothenberger, K. Katsiev, Y. Losovyj, X. Zhang, P. A. Dowben, O. F. Mohammed, E. H. Sargent, O. M. Bakr, Science 2015, 347, 519.

[46] W. E. I. Sha, X. Ren, L. Chen, W. C. H. Choy, Appl. Phys. Lett. 2015, 106, 221104. 
[47] W. Nie, H. Tsai, R. Asadpour, J. C. Blancon, A. J. Neukirch, G. Gupta, J. J. Crochet, M.

Chhowalla, S. Tretiak, M. A. Alam, H. L. Wang, A. D. Mohite, Science 2015, 347, 522.

[48] A. Filippetti, P. Delugas, A. Mattoni, J. Phys. Chem. C 2014, 118, 24843.

[49] J. Y. Jeng, Y. F. Chiang, M. H. Lee, S. R. Peng, T. F. Guo, P. Chen, T. C. Wen, Adv. Mater. 2013, 25, 3727.

[50] J. H. Kim, P. W. Liang, S. T. Williams, N. Cho, C. C. Chueh, M. S. Glaz, D. S. Ginger, A. K. Y. Jen , Adv. Mater. 2015, 27, 695.

[51] T. Kirchartz, J. Nelson, Phys. Rev. B 2012, 86, 165201. 
Submitted to

Perovskite solar cells exhibit improved photovoltaic parameters with increasing perovskite grain size. The larger photocurrent is due to the enhanced absorption efficiency for thicker perovskite layers. The larger open-circuit voltage $\left(V_{\mathrm{OC}}\right)$ is ascribed to the reduced trap-assisted recombination for the larger grains. As a result, the power conversion efficiency exceeds $19 \%$ at best. Further improvement in $V_{\mathrm{OC}}$ would be possible if trap density were reduced.

Keyword: halide perovskites; grain sizes; open-circuit voltages; direct recombinations; trapassisted SRH recombinations

H. D. Kim, Prof. H. Ohkita,* Prof. H. Benten, Prof. S. Ito

Photovoltaic Performance of Perovskite Solar Cells with Different Grain Sizes

ToC figure ((55 mm broad, $50 \mathrm{~mm}$ high, or $110 \mathrm{~mm}$ broad, $20 \mathrm{~mm}$ high))

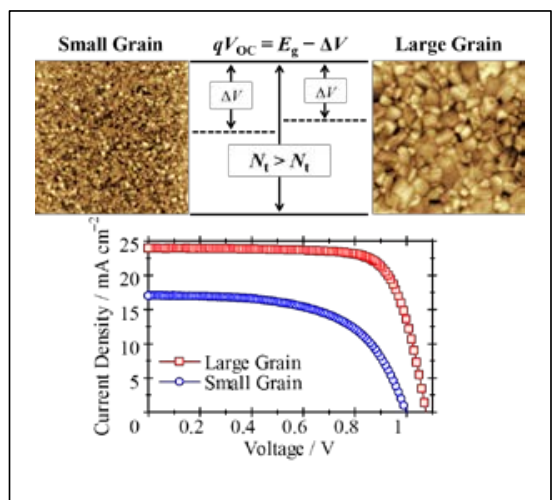


Copyright WILEY-VCH Verlag GmbH \& Co. KGaA, 69469 Weinheim, Germany, 2013.

\section{Supporting Information}

\section{Photovoltaic Performance of Perovskite Solar Cells with Different Grain Sizes}

Hyung Do Kim, Hideo Ohkita, * Hiroaki Benten, and Shinzaburo Ito

H. D. Kim, Dr. H. Ohkita, Dr. H. Benten, Prof. S. Ito

Department of Polymer Chemistry, Graduate School of Engineering, Kyoto University,

Katsura, Nishikyo, Kyoto 615-8510, Japan

E-mail: ohkita@photo.polym.kyoto-u.ac.jp

Dr. H. Ohkita

Japan Science and Technology Agency (JST), PRESTO, 4-1-8 Honcho, Kawaguchi, Saitama 332-0012, Japan. 


\section{Experimental}

\section{Submitted to

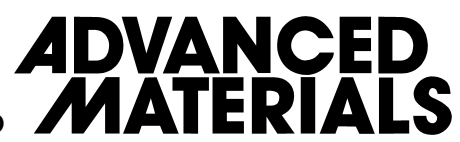

Materials and Sample Preparation. A methanol solution of methylamine (90 mL, 40\%, 0.882 M; Wako Pure Chemical Industries, Ltd.) was added drop wise over $10 \mathrm{~min}$ to an aqueous solution of HI (96.9 mL, 57 wt\%, 1.29 M; Wako Pure Chemical Industries Ltd., Japan) in a 500 $\mathrm{mL}$ round bottom flask at $0{ }^{\circ} \mathrm{C}$, and then stirred for $2 \mathrm{~h}$. The precipitates were recovered by evaporation at $50^{\circ} \mathrm{C}$ for $30 \mathrm{~min}$. The resultant yellowish raw products were dissolved in ethanol, recrystallized from diethyl ether, and then finally filtered. These steps were repeated three times. After filtration, the white solid products $\mathrm{CH}_{3} \mathrm{NH}_{3} \mathrm{PbI}_{3}\left(\mathrm{MAPbI}_{3}\right)$ were dried at $60{ }^{\circ} \mathrm{C}$ in a vacuum oven for $24 \mathrm{~h}$. Stock solutions $\left(\mathrm{MAPbI}_{3}\right)$ of $25 \mathrm{wt} \%\left(316 \mathrm{mg} \mathrm{mL}{ }^{-1}\right), 45 \mathrm{wt} \%$ (778 $\left.\mathrm{mg} \mathrm{mL}{ }^{-1}\right)$, and $55 \mathrm{wt} \%\left(1160 \mathrm{mg} \mathrm{mL}^{-1}\right.$ ) were prepared by mixing $\mathrm{CH}_{3} \mathrm{NH}_{3} \mathrm{I}$ (MAI) with purified $\mathrm{PbI}_{2}$ (Tokyo Chemical Industry Co., Ltd., Japan) at a molar ratio of 1 to 1 in anhydrous $N, N$ dimethylformamide (DMF, 99.8\%, Sigma-Aldrich) and then stirred at $70{ }^{\circ} \mathrm{C}$ overnight in a nitrogen-filled glove box $\left(\mathrm{H}_{2} \mathrm{O}\right.$ and $\left.\mathrm{O}_{2}<1 \mathrm{ppm}\right)$.

Fabrication of $\mathrm{MAPbI}_{3}$ Perovskite Solar Cells. A dense layer of $\mathrm{TiO}_{2}(\sim 40 \mathrm{~nm})$ was coated atop a UV-ozone cleaned FTO-coated glass substrate (sheet resistance of $12 \Omega$ per square, 25 $\mathrm{mm} \times 25 \mathrm{~mm}$, Asahi Glass Co., Ltd., Japan) by spray-pyrolysis at $470{ }^{\circ} \mathrm{C}$ using a bis(isopropoxide)bis(acetylacetonato)titanium(IV) solution (75 wt\% in 2-propanol, SigmaAldrich) diluted in ethanol (1:39, volume ratio). To deposit perovskite films, these dense- $\mathrm{TiO}_{2}$ substrates were transferred into an inert glove box under a nitrogen atmosphere $\left(\mathrm{H}_{2} \mathrm{O}\right.$ and $\mathrm{O}_{2}<$ $1 \mathrm{ppm})$. The $\mathrm{MAPbI}_{3}$ solution $(0.13 \mathrm{~mL})$ was first dropped onto the center of a dense- $\mathrm{TiO}_{2}$ coated FTO substrate. The substrate was firstly spun at $5000 \mathrm{rpm}$ for $30 \mathrm{~s}$, and after $6 \mathrm{~s}$ anhydrous chlorobenzene (CB, 99.8\%, Sigma-Aldrich, $0.3 \mathrm{~mL}$ ) was quickly dropped onto the center of substrate. The instant color change of films from yellow to brown was observed upon dropping CB solvent. The resulting dark brown films were dried at $100{ }^{\circ} \mathrm{C}$ for $10 \mathrm{~min}$. The hole-transporting layer was deposited on the perovskite layer by spin-coating at $4000 \mathrm{rpm}$ for $30 \mathrm{~s}$ from a solution of 2,2',7,7'-tetrakis( $N, N$-di-p-methoxyphenylamine)-9,9-spirobifluorene 
Submitted to

(spiro-OMeTAD, Merck, $72.3 \mathrm{mg}$ ) in anhydrous chlorobenzene (CB, 99.8\%, Sigma-Aldrich, $1.0 \mathrm{~mL}$ ) containing $28.8 \mu \mathrm{L}$ of 4-tert-butylpyridine (Aldrich) and $17.5 \mu \mathrm{L}$ of lithium bis(trifluoromethanesulfonyl)imide (Li-TFSI) solution (520 mg Li-TFSI in $1 \mathrm{~mL}$ acetonitrile, Sigma-Aldrich). Finally, $80 \mathrm{~nm}$ of gold was thermally evaporated on top of the active layer under high vacuum $\left(2.5 \times 10^{-4} \mathrm{~Pa}\right)$. The final layered structure of these perovskite solar cells is $\mathrm{FTO} /$ dense- $\mathrm{TiO}_{2} / \mathrm{CH}_{3} \mathrm{NH}_{3} \mathrm{PbI}_{3} / \mathrm{HTM} / \mathrm{Au}$. At least 12 devices were fabricated to ensure the reproducibility of the $J-V$ characteristics.

Measurements. $J-V$ characteristics were measured with a DC voltage and current source/monitor (Keithley, 2611B) in the dark and under the illumination with AM1.5G simulated solar light with $100 \mathrm{~mW} \mathrm{~cm}^{-2}$. The light intensity was corrected with a calibrated silicon photodiode reference cell (Bunkoh-Keiki, BS-520). The intensity-dependent $J-V$ characteristics were measured by using the neutral density (ND) filters. The EQE spectra were measured by using an ECT-250D integrated system made by Bunko-Keiki Co. under monochromatic light illumination from a 300-W xenon lamp with optical cut filters and a monochromator. The power of the incident monochromatic light was kept under $0.05 \mathrm{~mW} \mathrm{~cm}^{-2}$, which was measured by a calibrated silicon reference cell. All devices were measured in a nitrogen atmosphere with a metal mask to give an active area of $0.09 \mathrm{~cm}^{2}$. The film surface morphology and the film thickness were measured with an atomic force microscope (Shimadzu, SPM-9600) with a silicon probe (Olympus, a force constant of $\sim 0.15 \mathrm{~N} \mathrm{~m}^{-1}$ ) in contact mode and with a scanning electron microscope (Keyence, VE-9800). 


\section{AFM Images}

\section{Submitted to

Figure S1 shows the AFM height images of an $\mathrm{MAPbI}_{3}$ perovskite film via a conventional one-step spin coating procedure using a $25 \mathrm{wt} \%$ stock solution. The resultant film morphology exhibits textures of elongated crystal structures with an incomplete coverage on the substrate. These trends are in good agreement with the previous report. ${ }^{[\mathrm{S} 1]}$

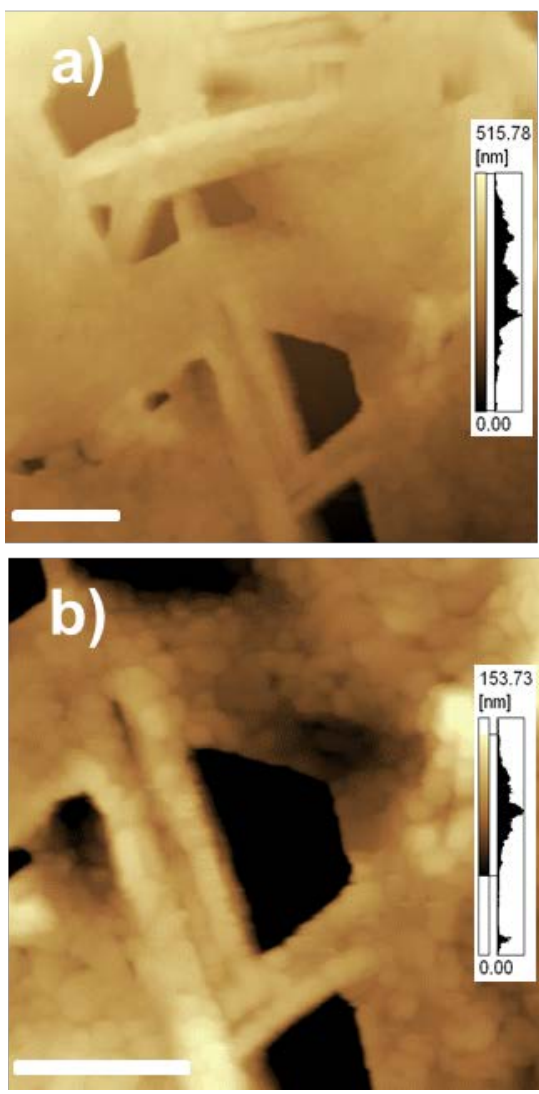

Figure S1. Atomic force microscope (AFM) height images of an $\mathrm{MAPbI}_{3}$ perovskite film via a conventional spin-coating procedure using a $25 \mathrm{wt} \%$ stock solution. The image areas are a) $5 \mu \mathrm{m} \times 5 \mu \mathrm{m}$ and b) $3 \mu \mathrm{m} \times 3 \mu \mathrm{m}$. The scale bars are $1 \mu \mathrm{m}$. 


\section{SEM Images}

\section{Submitted to

Figure S2 shows the SEM images of MAPbI 3 perovskite films prepared from 25 wt $\%$, 45 wt $\%$, and 55 wt $\%$ stock solution. The resultant films are dense and pin-hole free with relatively uniform grain sizes over the entire substrate. The grain size of $\mathrm{MAPbI}_{3}$ increases with increasing concentration of the stock solution used to prepare the perovskite layer. This is consistent with that observed for the AFM images as shown in Figure 1.
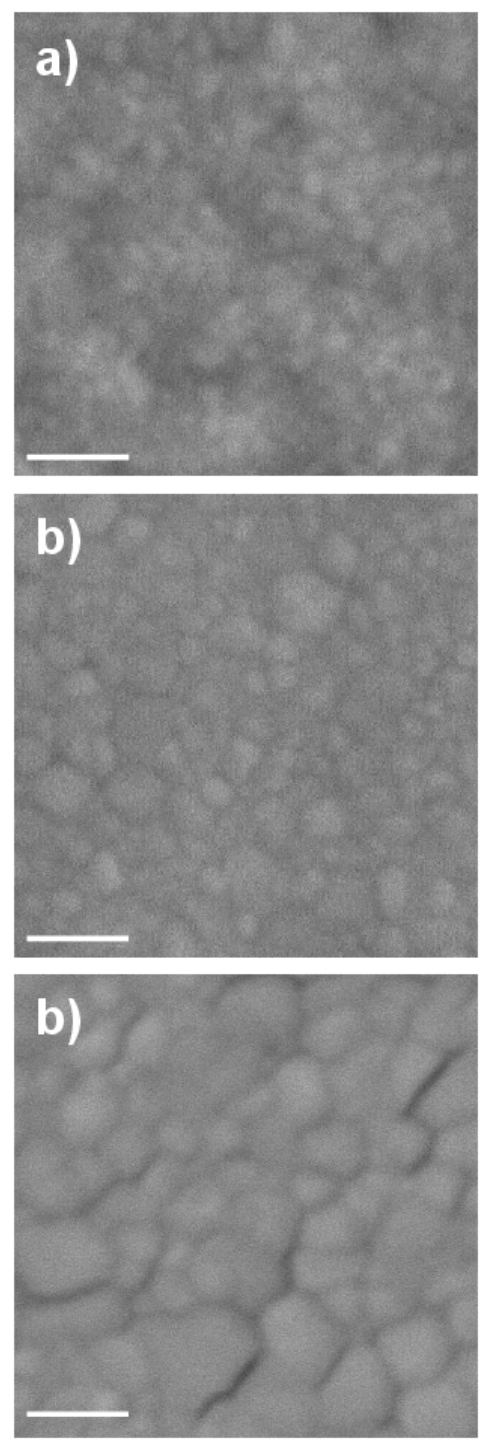

Figure S2. SEM images of $\mathrm{MAPbI}_{3}$ perovskite films prepared from a) $25 \mathrm{wt} \%$ stock solution, b) $45 \mathrm{wt} \%$ stock solution, and c) $55 \mathrm{wt} \%$ stock solution. The scale bars correspond to $500 \mathrm{~nm}$ in length. 
Submitted to

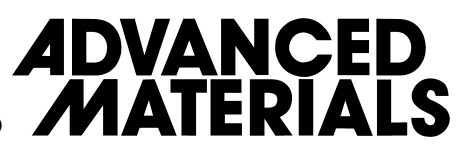

Figure S3 shows the cross-sectional SEM image of an $\mathrm{MAPbI}_{3}$ perovskite solar cell wih a grain size of $\sim 500 \mathrm{~nm}$. The $\mathrm{MAPbI}_{3}$ perovskite film fabricated by the FDC procedure consists of monograins in the direction normal to the substarte.

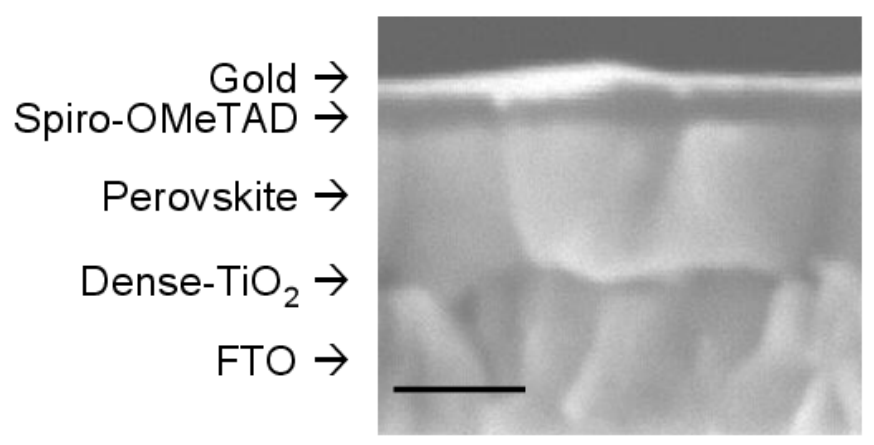

Figure S3. Cross-sectional SEM image of an $\mathrm{MAPbI}_{3}$ perovskite solar cell prepared from 55 wt\% stock solution. The scale bar corresponds to $500 \mathrm{~nm}$ in length. 


\section{Device Parameters}

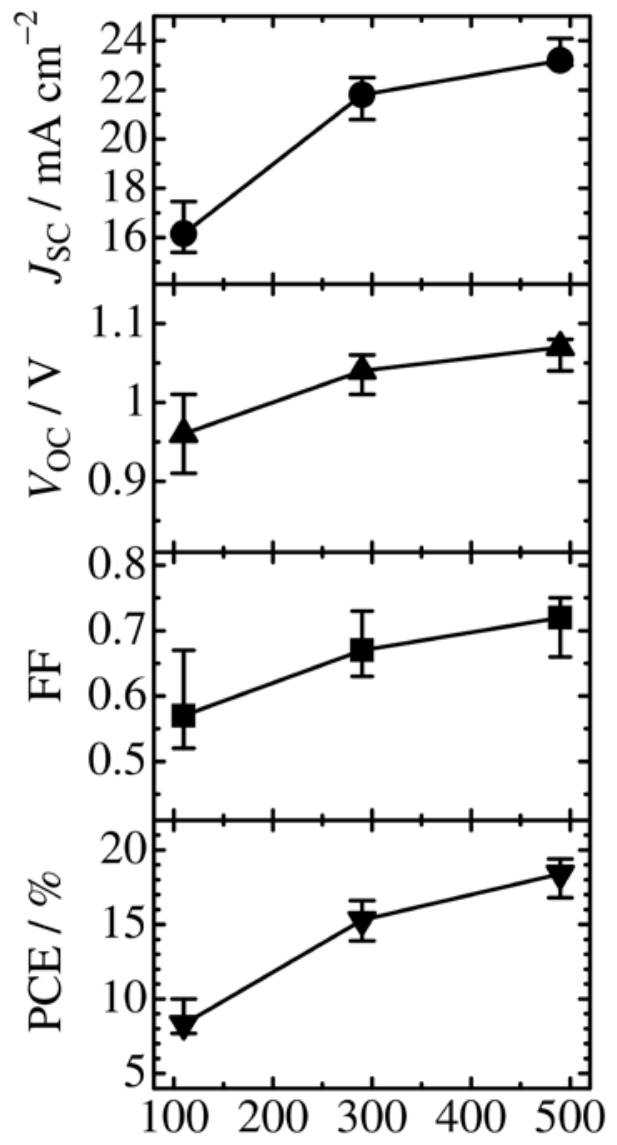

Grain size of $\mathrm{MAPbI}_{3} / \mathrm{nm}$

Figure S4. Device parameters of $\mathrm{MAPbI}_{3}$ perovskite solar cells measured from 1.2 to $-0.10 \mathrm{~V}$ (reverse scan) with a delay time of $1 \mathrm{~s}$ as a function of the grain size of $\mathrm{MAPbI}_{3}$ perovskites. All the devices were measured in a nitrogen atmosphere with a metal mask to give an active area of $0.09 \mathrm{~cm}^{2}$ and averaged for at least 12 devices. 
Submitted to

\section{ADVANCED MATERIALS}

\section{Steady-State Photocurrent and $J-V$ Characteristics}

Figure S5a shows the steady-state photocurrent measured by keeping the solar cells with a grain size of $\sim 500 \mathrm{~nm}$ at a maximum power point voltage $(0.88 \mathrm{~V})$ during $120 \mathrm{~s}$. This indicates that the stabilized photocurrent can be obtained after the solar cell was illuminated for $60 \mathrm{~s}$. Figure S5b shows the $J-V$ characteristics of $\mathrm{MAPbI}_{3}$ perovskite solar cells with a grain size of $\sim 500 \mathrm{~nm}$ measured from -0.10 to $1.2 \mathrm{~V}$ (forward scan), from 1.2 to $-0.10 \mathrm{~V}$ (reverse scan) at a delay time of $1 \mathrm{~s}$, and in the steady state. The steady-state $J-V$ characteristics was measured by

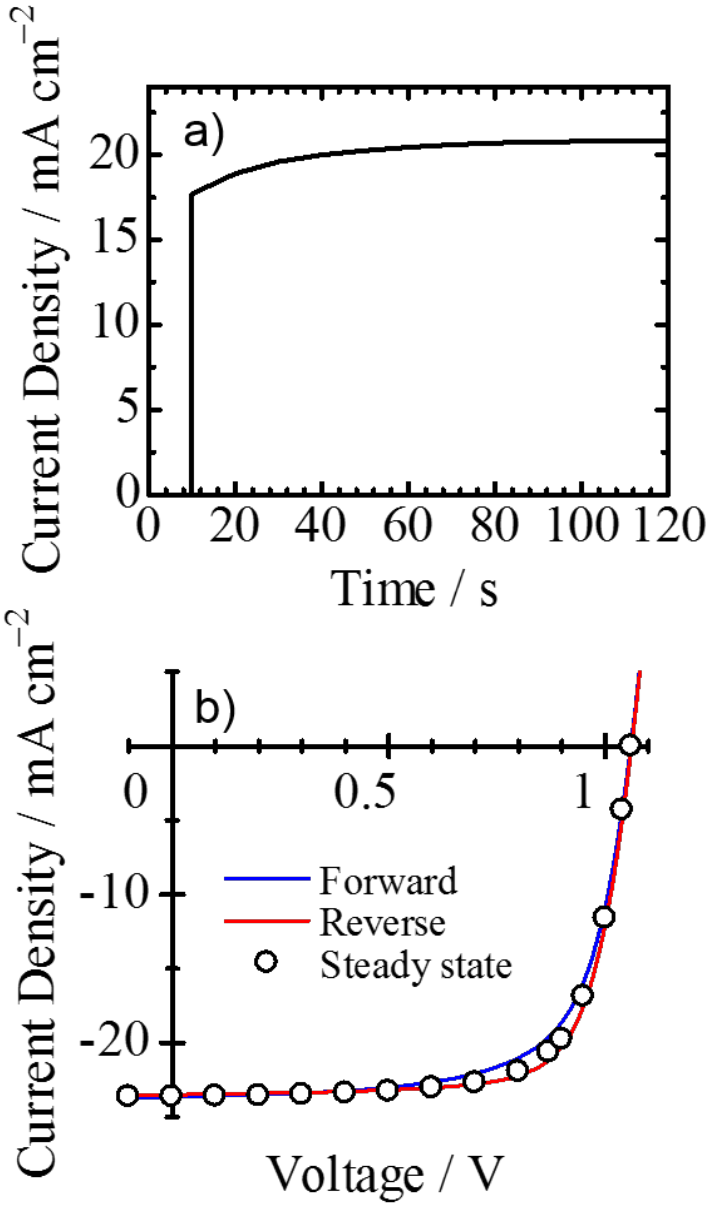

Figure S5. a) Steady-state photocurrent of an $\mathrm{MAPbI}_{3}$ perovskite solar cell with a grain size of $\sim 500 \mathrm{~nm}$ measured at a maximum power point voltage $(0.88 \mathrm{~V})$ and b) $J-V$ characteristics of the corresponding solar cell measured from -0.10 to $1.2 \mathrm{~V}$ (forward scan), from 1.2 to $-0.10 \mathrm{~V}$ (reverse scan) with a delay time of $1 \mathrm{~s}$, and in the steady state. The steady-state $J-V$ characteristics was measured by keeping the device at a constant voltage potential for $60 \mathrm{~s}$. All the devices were measured in a nitrogen atmosphere with a metal mask to give an active are of $0.09 \mathrm{~cm}^{2}$. 
Submitted to

keeping the corresponding device at a constant voltage potential for $60 \mathrm{~s}$, in accordance with the literature. ${ }^{[\mathrm{S} 2]}$ The resultant device parameters are summarized in Table S1.

Table S1. Device parameters of the $\mathrm{MAPbI}_{3}$ perovskite solar cell in Figure S5b.

\begin{tabular}{ccccc}
\hline Scan mode & $J_{\mathrm{SC}} / \mathrm{mA} \mathrm{cm}^{-2}$ & $V_{\mathrm{OC}} / \mathrm{V}$ & FF & PCE / \% \\
\hline Forward scan & 23.6 & 1.06 & 0.683 & 17.1 \\
Reverse scan & 23.6 & 1.06 & 0.740 & 18.5 \\
Steady state & 23.6 & 1.06 & 0.728 & 18.2 \\
\hline
\end{tabular}




\section{Distribution of Photovoltaic Performance}

Submitted to
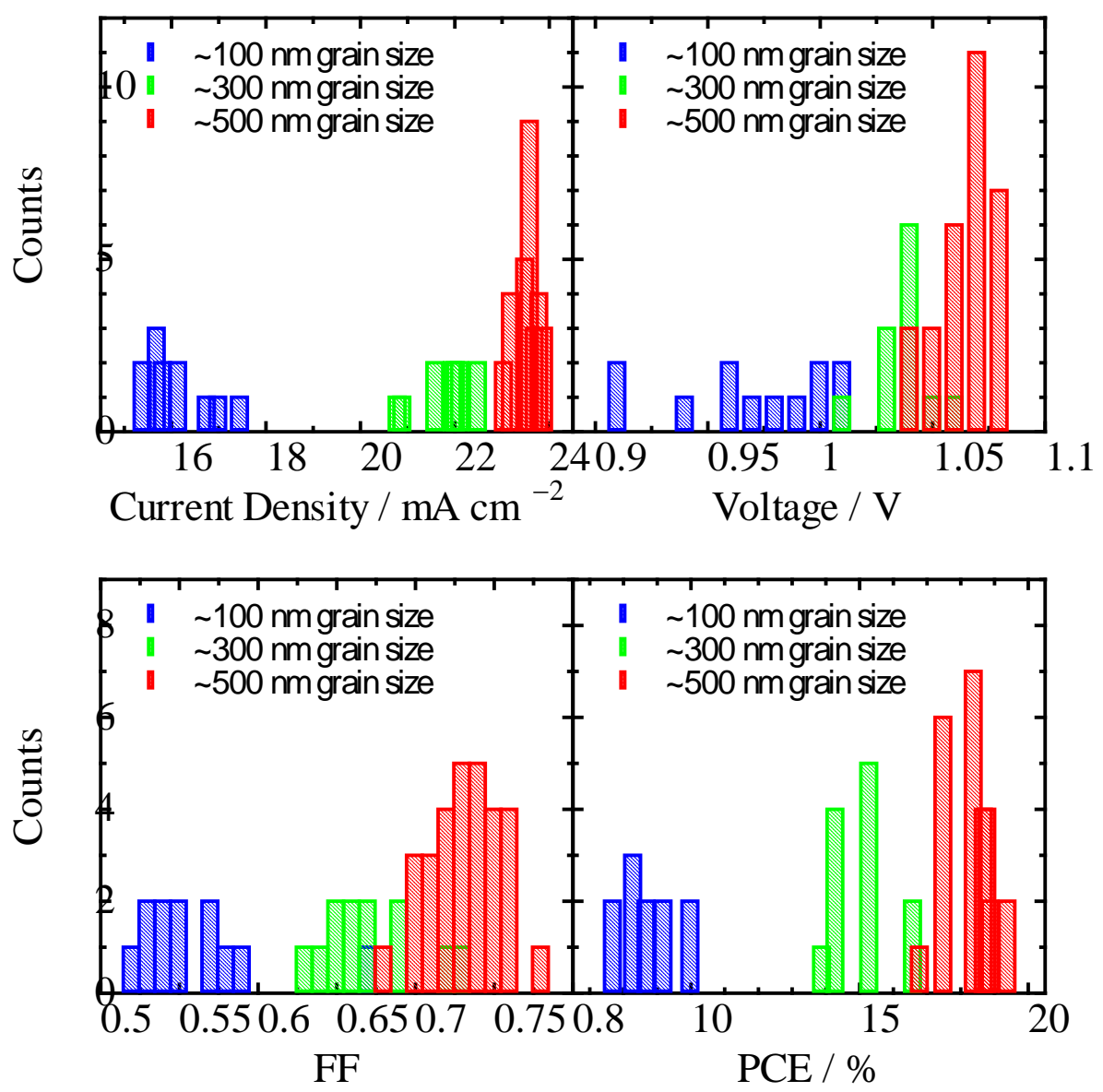

Figure S6. Histograms of the device parameters for $\mathrm{MAPbI}_{3}$ perovskite solar cells measured from 1.2 to $-0.10 \mathrm{~V}$ (reverse scan) with a delay time of $1 \mathrm{~s}$. Device parameters for the $\sim 500$ $\mathrm{nm}$ grain size are averaged from 30 devices and for the others from 12 devices to ensure the reproducibility of the $J-V$ characteristics. 
7. Long-Term Stability of MAPbI 3 Perovskite Solar Cells

Submitted to

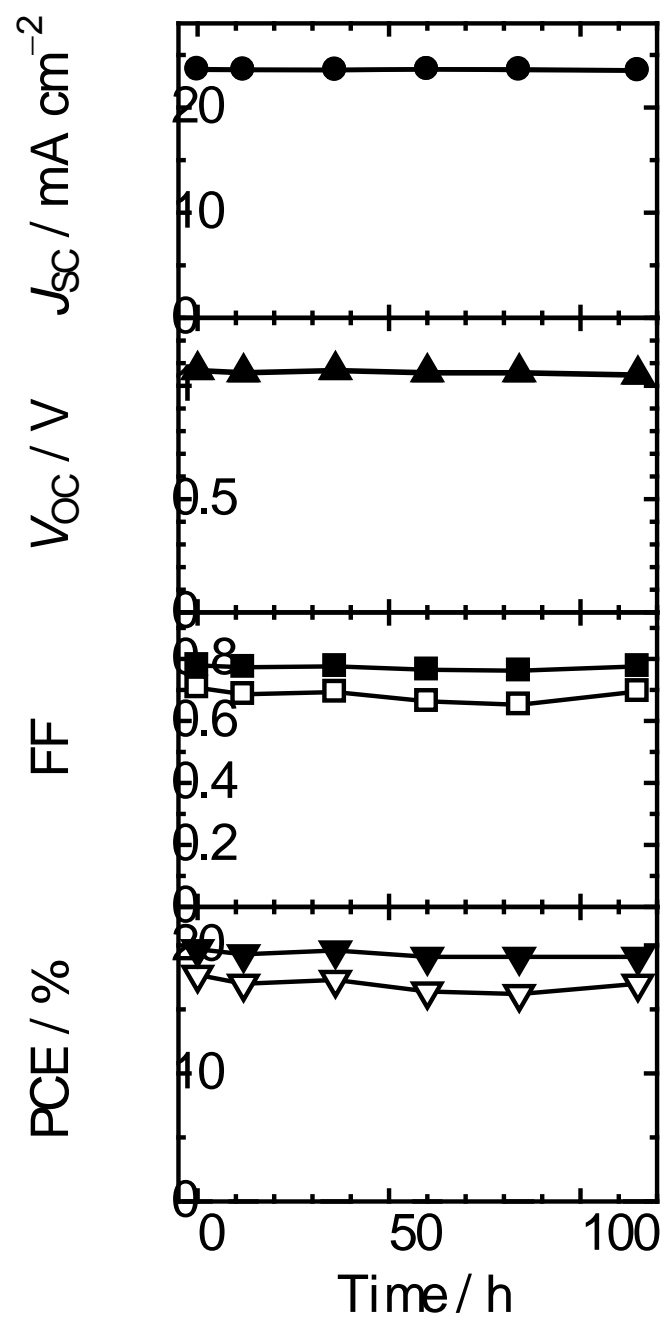

Figure S7. Long-term stability of an $\mathrm{MAPbI}_{3}$ perovskite solar cell with a grain size of $\sim 500$ $\mathrm{nm}$ measured from -0.10 to $1.2 \mathrm{~V}$ (forward scan), from 1.2 to $-0.10 \mathrm{~V}$ (reverse scan) with a delay time of $1 \mathrm{~s}$ : the open and closed symbols demonstrate photovoltaic parameters in the forward and reverse scan, respectively. This device was measured in a nitrogen atmosphere with a metal mask to give an active area of $0.09 \mathrm{~cm}^{2}$. During each measurement interval, the device was stored in a nitrogen-filled glove box $\left(\mathrm{H}_{2} \mathrm{O}\right.$ and $\left.\mathrm{O}_{2}<1 \mathrm{ppm}\right)$. 


\section{Submitted to

\section{Hysteresis of MAPbI ${ }_{3}$ Perovskite Solar Cells}

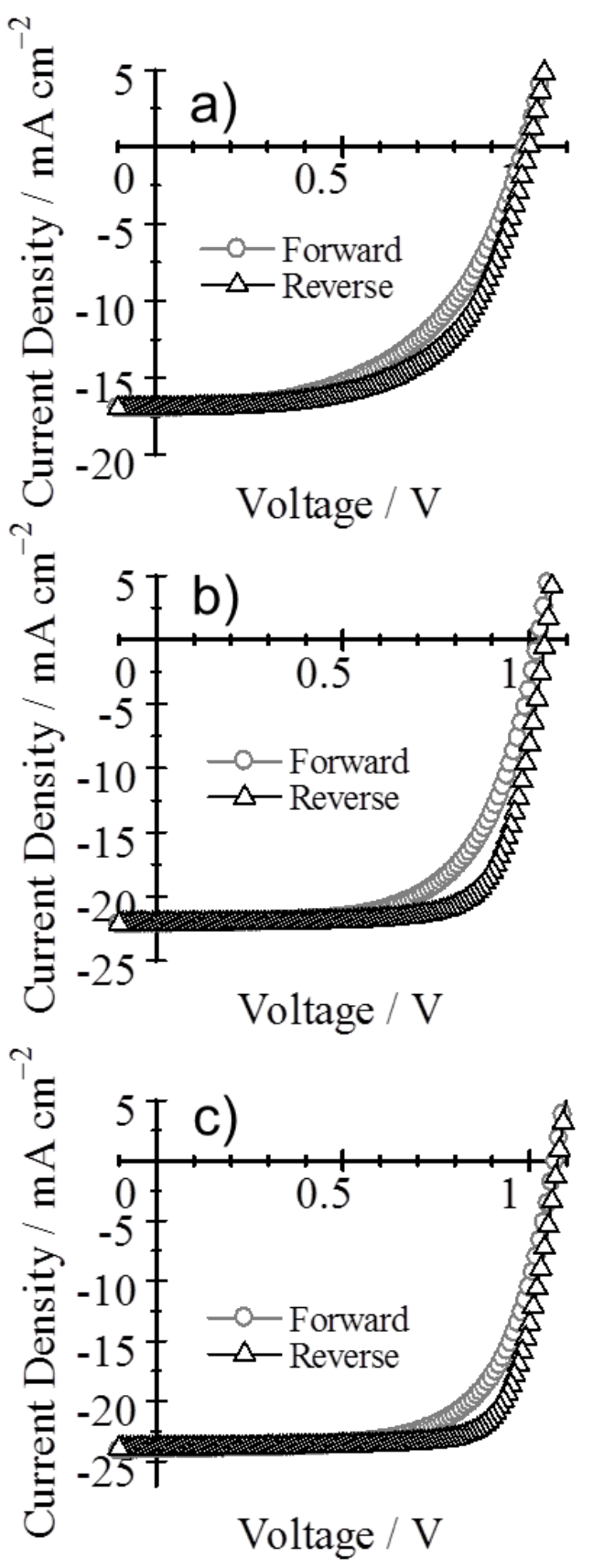

Figure S8. $J-V$ characteristics of $\mathrm{MAPbI}_{3}$ perovskite solar cells with different grain sizes measured from -0.10 to $1.2 \mathrm{~V}$ (forward scan), from 1.2 to $-0.10 \mathrm{~V}$ (reverse scan) with a delay time of $1 \mathrm{~s}: \mathrm{MAPbI}_{3}$ perovskite solar cells with a grain size of a) 100 nm, b) $\sim 300 \mathrm{~nm}$, and c) $\sim 500 \mathrm{~nm}$. All the devices were measured in a nitrogen atmosphere with a metal mask to give an active of $0.09 \mathrm{~cm}^{2}$. 


\section{References}

[S1] M. Xiao, F. Huang, W. Huang, Y. Dkhissi, Y. Zhu, J. Etheridge, A. Gray-Weale, U. Bach, Y. B. Cheng, L. Spiccia, Angew. Chem. 2014, 126, 10056.

[S2] J. A. Christians, J. S. Manser, P. V. Kamat, J. Phys. Chem. Lett. 2015, 6, 852. 